\title{
Estrategias de enseñanza para la comprensión: un enfoque alternativo
}

Costamagna, Alicia (*); Manuale, Marcela (*)

\section{Resumen}

La búsqueda de estrategias centradas en la comprensión de los aprendizajes y la reorganización de los contenidos de la enseñanza guían nuestro proyecto de investigación, indagando cómo impactan en el aprendizaje de los alumnos las estrategias que reordenan los contenidos según diferentes tópicos generativos, elaborados por los equipos docentes de las cátedras involuctradas.

(Este trabajo es un avance del proyecto $C A I+D$ 2000: "Investigación del valor de la organización de los contenidos a través de tópicos generativos en el marco de una enseñanza para la comprensión, en la carrera de Bioquímica", cuyas autoras son directora y codirectora del mismo). 